\title{
Consumer mobility predicts impacts of herbivory across an environmental stress gradient
}

\author{
Robert W. Lamb, ${ }^{1,2,3}$ Franz Smith, ${ }^{1}$ and Jon D. Witman ${ }^{1}$ \\ ${ }^{1}$ Ecology and Evolutionary Biology Department, Brown University, 80 Waterman Street, Box G-W, Providence, Rhode Island 02912 \\ USA \\ ${ }^{2}$ Biology Department, Woods Hole Oceanographic Institution, 266 Woods Hole Road, MS 50, Woods Hole, Massachusetts 02543 \\ $U S A$
}

Citation: Lamb, R. W., F. Smith, and J. D. Witman. 2019. Consumer mobility predicts impacts of herbivory across an environmental stress gradient. Ecology 00(00):e02910. 10.1002/ecy.2910

\begin{abstract}
Environmental stress impedes predation and herbivory by limiting the ability of animals to search for and consume prey. We tested the contingency of this relationship on consumer traits and specifically hypothesized that herbivore mobility relative to the return time of limiting environmental stress would predict consumer effects. We examined how wave-induced water motion affects marine communities via herbivory by highly mobile (fish) vs. slowmoving (pencil urchin) consumers at two wave-sheltered and two wave-exposed rocky subtidal locations in the Galapagos Islands. The exposed locations experienced 99th percentile flow speeds that were 2-5 times greater than sheltered locations, with mean flow speeds $>33 \mathrm{~cm} / \mathrm{s}$ vs. $<16 \mathrm{~cm} / \mathrm{s}, 2-7$ times higher standing macroalgal cover and 2-3 times lower cover of crustose coralline algae than the sheltered locations. As predicted by the environmental stress hypothesis (ESH), there was a negative relationship between mean flow speed and urchin abundance and herbivory rates on Ulva spp. algal feeding assays. In contrast, the biomass of surgeonfishes (Acanthuridae) and parrotfishes (Labridae: Scarinae) was positively correlated with mean flow speed. Ulva assays were consumed at equal rates by fish at exposed and sheltered locations, indicating continued herbivory even when flow speeds surpassed maximum reported swimming speeds at a rate of 1-2 times per minute. Modeled variation in fish species richness revealed minimal effects of diversity on herbivory rates at flow speeds $<40 \mathrm{~cm} / \mathrm{s}$, when all species were capable of foraging, and above $120 \mathrm{~cm} / \mathrm{s}$, when no species could forage, while increasing diversity maximized herbivory rates at flow speeds of 40-120 cm/s. Two-month herbivore exclusion experiments during warm and cool seasons revealed that macroalgal biomass was positively correlated with flow speed. Fish limited macroalgal development by $65-91 \%$ at one exposed location but not the second and by $70 \%$ at the two sheltered locations. In contrast, pencil urchins did not affect algal communities at either exposed location, but reduced macroalgae by $87 \%$ relative to controls at both sheltered locations. We propose an extension of the ESH that is contingent upon mobility to explain species-specific changes in feeding rates and consumer effects on benthic communities across environmental gradients.
\end{abstract}

Key words: community ecology; environmental stress; fish; flow; Galapagos; herbivory; rocky reefs, subtidal; swimming speed; urchins; waves.

\section{INTRODUCTION}

Environmental gradients have long been known to influence the diversity and abundance of species (Humboldt and Bonpland 1805). Ecologically relevant gradients in physical parameters such as light and temperature exist where the probability of environmental stress-induced mortality changes through space or time (Denny et al. 1985). Environmental stress is a physical parameter that reduces the ability of an organism to

Manuscript received 13 March 2019; revised 14 August 2019; accepted 3 September 2019. Corresponding Editor: Steven Morgan.

${ }^{3}$ E-mail: robert_lamb@brown.edu carry out biological functions such as maintaining homeostasis, feeding, or reproducing, and is speciesspecific (Bijlsma and Loeschcke 2005). Stress gradients act as an environmental filter on the pool of potential species forming a community (Kraft et al. 2015). Variation in environmental stress also alters the strength and sign of biotic interactions: a high frequency of stress limits the ability of animals to forage and reduces the influence of predation on community composition relative to competition (Connell 1975, Menge and Sutherland 1976) and facilitation through habitat amelioration (Bertness and Callaway 1994, He and Bertness 2014). However, observations of ecological variation along environmental gradients are insufficient for developing a mechanistic understanding of the contributions of direct 
(physical) vs. indirect (biological) effects of environmental variation on community composition. This requires quantification of the magnitude of environmental thresholds that signify stressful conditions for each species, and the frequency with which these thresholds are surpassed.

Because environmental stress varies substantially over a relatively small area in marine intertidal ecosystems, the coastal fringe was used as a testing ground for developing early foundational theories such as the environmental stress hypothesis (ESH; Sanders 1969, Menge and Sutherland 1976, 1987), which predicts that environmental stress will decrease the effect of predation on basal species (sessile invertebrates and plants; sensu Pimm 1982), because consumers are limited from moving about their habitat to forage. The ESH expects basal species to occupy a wider optimal range and continue to compete for resources in areas of high environmental stress where the animals that feed on them have been excluded. This is because sessile organisms suffer a greater likelihood of stress-induced mortality because of their immobility, which imposes selection for adaptations to a wide range of environmental conditions (Connell 1975, Menge 1978). In contrast, mobile consumers can elect benign habitats postsettlement, a behavioral mechanism that is favored for minimizing exposure to stress (Bijlsma and Loeschcke 2005). As a result, exposure of intertidal communities to the acceleration, drag, and lift forces generated by waves (Denny et al. 1985) produces a reliable, repeated pattern of decreasing effects of consumers on basal species with increasing wave exposure (Menge 1978, Siddon and Witman 2003, Taylor and Schiel 2010). Benthic algae and sessile invertebrates growing on hard substrates are also directly influenced by wave-induced water motion, which increases growth and productivity (Leigh et al. 1987, Hurd 2000) but also leads to mortality via dislodgement (Paine and Levin 1981, Witman and Suchanek 1984), limiting survival to drag-resistant forms (Denny et al. 1985, Tuya and Haroun 2006).

Although the effects of environmental stress on community structure have been extensively studied in rocky marine (Menge et al. 2002) and estuarine (Leonard et al. 1998) intertidal ecosystems, comparatively few studies have experimentally tested its role in subtidal reefs (Witman 1987, Witman and Grange 1998, Siddon and Witman 2003, Taylor and Schiel 2010, Bennett et al. 2015). This may have skewed scientific perspective towards that of benthic invertebrates such as sea urchins, sea stars, mollusks, and crabs, which are dominant consumers in intertidal ecosystems (Connell 1961). Predation by more mobile vertebrate predators is generally limited to high tide for fishes (Horn et al. 1999, Ojeda and Munoz 1999) and low tide for birds (Ellis et al. 2007). In contrast, a potential advantage to subtidal tests of the ESH is the abundance of fast-moving, visually acute predators such as fishes and other vertebrates in these ecosystems. The diversity of body plans, swimming modes and speeds represented by consumers inhabiting subtidal reefs presents a unique opportunity to understand how species mobility mediates the effects of environmental stress and impacts community organization (Edwards et al. 1982). Highly mobile animals can avoid stress during severe periods and return during milder periods (Menge and Sutherland 1987), which ties the magnitude of their ecological impact to the periodicity of stress at a particular location (Witman and Dayton 2001). We propose that the speed with which an animal can navigate among resource patches (mobility) relative to the frequency with which environmental tolerance thresholds are surpassed is a fundamental property governing foraging behavior and the ecological effects of consumers.

Herbivory is one of the most important biological interactions shaping the structure of marine reefs through its powerful influence on benthic organisms (Hay 1981, Lewis 1986). Tropical benthic communities are particularly susceptible to ecological effects of grazing by herbivorous fishes and sea urchins (Steneck et al. 2017). Herbivorous fishes can exert immense consumer pressures on benthic algae (up to $156,000 \mathrm{bites} / \mathrm{m}^{2} / \mathrm{d}$; Hatcher 1981). Sea urchins can also reach very high densities, but are slow-moving, making them susceptible to dislodgement (Tuya et al. 2007) and reduced foraging ability (Siddon and Witman 2003) under conditions of high wave exposure. Therefore, herbivorous fishes may have a distinct foraging advantage over urchins on waveswept reefs, because their greater mobility allows fish to avoid or minimize exposure to physical stressors such as waves when and where they occur. For instance, urchin abundance and herbivory rates decrease with acidic $\mathrm{pH}$ levels around $\mathrm{CO}_{2}$ seeps in the Mediterranean Sea, because they are too slow to access algal food around the seeps and exit the acidified water before suffering detrimental effects (Baggini et al. 2015). In contrast, fish abundance and herbivory increase because fish can swim into the acidic area, feed on the abundant algae devoid of urchin grazing, and exit before negative effects of the low pH accumulate. Similarly, fish may be able to navigate between sets of high waves to avoid damaging conditions and continue foraging on subtidal reefs, in contrast to urchins. We propose that the ESH is contingent on consumer traits such as mobility. If herbivorous fishes can navigate extreme oscillatory flow speeds generated by waves better than slower-moving benthic invertebrate grazers, they may be able to continue to feed on and regulate benthic algal populations even after benthic invertebrate grazers have been prevented from foraging. Since herbivory by fish and urchins has different effects on benthic algal composition (Carpenter 1986), wave exposure should influence benthic algal communities via selective exclusion of slower over faster consumers, in addition to direct effects of water motion on algal growth rates (Hurd 2000).

We studied the effects of wave exposure on rocky subtidal reefs at two sites in the Galapagos Islands to examine the effects of wave stress on herbivory and the 
consequences of stress-mediated herbivory for the structure of benthic communities. We sought to partition the direct effects of wave exposure as an environmental filter on each species in the community from the indirect effects of wave exposure via biological interactions. We tested four hypotheses that potentially explain the effects of environmental stress generated by waveinduced water motion on patterns of herbivory and the structure of benthic algal communities (Table 1): (1) algal and herbivore communities vary along a wave exposure gradient (environmental gradients); (2) waveinduced water motion directly affects the abundance and biomass of benthic algae, fish, and urchins (environmental filtering); (3a) herbivore feeding rates and influence on benthic algal biomass decreases with increasing wave exposure (ESH); (3b) fast-moving herbivores exert strong effects on benthic algal biomass regardless of wave exposure, whereas slow-moving benthic herbivores control algal biomass only when sheltered from waves (ESH contingent on mobility); and (4) flow-driven variation in herbivory rates by fish and urchins causes differences in benthic algal community composition (predation).

Here we show that the biomass of benthic algae and several herbivorous fish species increase with greater flow speeds, whereas urchins decrease in abundance, supporting environmental filtering of slower herbivores. We also show that although foraging rates and effects on benthic communities of urchins decrease with wave stress in accordance with ESH predictions, rates of fish herbivory are actually higher at more wave-exposed locations. At low-flow speeds, herbivory by urchins leads to a crustose, low-diversity algal community, but fish have a stronger effect on algae than urchins at high flow speeds. These results support the contingency of the
ESH on consumer traits, predicting that environmental stress constraints on the presence and ecological impact of consumers is dependent on stress-tolerance thresholds for each species, and the frequency with which these thresholds are surpassed relative to consumer mobility.

\section{Methods}

\section{Study sites, organisms, and wave-induced water motion}

We carried out this research in the Galapagos Islands, located $906 \mathrm{~km}$ east of mainland Ecuador in the Tropical Eastern Pacific. Long-period waves originating from storms in the Southern Ocean hit the south-facing sides of most of the archipelago during the cool season between May and December, and then switch to weaker, northerly swells during the warm season from January to April (Houvenaghel 1978). Equatorial upwelling yields productive planktonic and benthic algal communities that in turn sustain a high biomass and diversity of both subtropical and tropical lineages of herbivorous fishes and macroinvertebrates (Edgar et al. 2004, Witman et al. 2010, Quimbayo et al. 2018), none of which are actively targeted by the local artisanal fishing fleet (Zimmerhackel et al. 2015). Several species represent herbivorous fish families including surgeonfishes (Acanthuridae), parrotfishes (Labridae-Scarinae), and damselfishes (Pomacentridae; Grove and Lavenberg 1997), which vary considerably in their ability to forage in high wave-induced water motion (Fulton and Bellwood 2005). The most abundant large benthic invertebrate grazer in the Galapagos is Eucidaris galapagensis (Brandt and Guarderas 2002, Edgar et al. 2004), a pencil urchin that has low attachment strength to the substrate (Brandt 2012). Eucidaris is a generalist that

TABLE 1. List of hypotheses, predicted outcomes, and relevant conceptual models tested for the effects of wave-induced water motion (environmental stress) on marine communities.

\begin{tabular}{|c|c|c|c|}
\hline Question & Hypothesis & Prediction & Model \\
\hline $\begin{array}{l}\text { 1. Do subtidal marine } \\
\text { communities vary } \\
\text { along a wave exposure } \\
\text { gradient? }\end{array}$ & $\begin{array}{l}\text { Wave-induced water motion } \\
\text { presents an environmental stress } \\
\text { to marine organisms via drag, lift, } \\
\text { and acceleration forces }\end{array}$ & $\begin{array}{l}\text { The richness and abundance of species will } \\
\text { vary between rocky reefs that are } \\
\text { exposed to or sheltered from high waves }\end{array}$ & $\begin{array}{l}\text { Environmental } \\
\text { gradients }\end{array}$ \\
\hline $\begin{array}{l}\text { 2. How do species vary } \\
\text { in their tolerance to } \\
\text { wave stress? }\end{array}$ & $\begin{array}{l}\text { Wave stress at exposed locations } \\
\text { prevents the establishment or } \\
\text { persistence of some species that } \\
\text { are successful in sheltered } \\
\text { locations }\end{array}$ & $\begin{array}{l}\text { Effects of wave stress on natural } \\
\text { abundances are positive, negative, or } \\
\text { neutral according to traits specific to } \\
\text { species or guilds of species }\end{array}$ & $\begin{array}{l}\text { Environmental } \\
\text { filtering }\end{array}$ \\
\hline \multirow[t]{2}{*}{$\begin{array}{l}\text { 3. How does wave stress } \\
\text { affect foraging rates? }\end{array}$} & $\begin{array}{l}\text { (a) Foraging rates by all consumers } \\
\text { are reduced by wave stress }\end{array}$ & $\begin{array}{l}\text { (a) Herbivory by fish and urchins is lower } \\
\text { at wave-exposed than wave-sheltered } \\
\text { locations }\end{array}$ & (a) ESH \\
\hline & $\begin{array}{l}\text { (b) Effects of wave stress on } \\
\text { foraging rates vary according to } \\
\text { consumer mobility }\end{array}$ & $\begin{array}{l}\text { (b) Herbivory by highly mobile fishes is } \\
\text { less susceptible to wave stress than slower } \\
\text { urchins }\end{array}$ & $\begin{array}{l}\text { (b) Mobility- } \\
\text { contingent } \\
\text { ESH }\end{array}$ \\
\hline $\begin{array}{l}\text { 4. How does variation in } \\
\text { consumer pressure } \\
\text { affect benthic } \\
\text { communities? }\end{array}$ & $\begin{array}{l}\text { Variation in guild-specific } \\
\text { herbivory rates associated with } \\
\text { wave exposure affects the } \\
\text { abundance and diversity of } \\
\text { benthic algae }\end{array}$ & $\begin{array}{l}\text { Fish and urchin grazing have different } \\
\text { effects on benthic algae, generating } \\
\text { differences in benthic algal biomass and } \\
\text { diversity between exposed and sheltered } \\
\text { locations }\end{array}$ & Predation \\
\hline
\end{tabular}


feeds on algae, barnacles, and corals (Glynn et al. 1979), and has substantial impacts on benthic algal cover (Witman et al. 2017), causing widespread urchin barrens in some places (Edgar et al. 2010). It wedges itself among rocks and crevices during the day using its strong spines, with most individuals emerging at night to feed out in the open in rocky habitats (Brandt and Guarderas 2002, Dee et al. 2012). Because E. galapagensis has poor attachment strength, we hypothesized that wave exposure may be a key environmental driver of the distribution and ecological impact of this important grazer species.

We selected two sites for surveys and field experiments located $30.6 \mathrm{~km}$ apart along the southern coast of Santa Cruz, the second largest of the Galapagos Islands: Islote Caamaño ("Caamaño": 0 $0^{\circ} 45^{\prime} 35.6^{\prime \prime} \mathrm{S}, 90^{\circ} 16^{\prime} 47.8^{\prime \prime} \mathrm{W}$ ) and Las Palmas Chicas ("Palmas": $0^{\circ} 40^{\prime} 42.6^{\prime \prime} \mathrm{S}, 90^{\circ} 32^{\prime} 35.4^{\prime \prime}$ W). At each study site, two locations were selected to maximize the local differential in wave exposure, with an "exposed" location directly facing the predominant southerly swell, and a "sheltered" location $\sim 100 \mathrm{~m}$ away, but behind a small peninsula that acted as a natural submerged breakwater (Appendix S1: Fig. S1). Temperature was measured every $10 \mathrm{~min}$ at each site between June 2015 and January 2018 using $\mathrm{HOBO}$ tidbit ${ }^{\circledR}$ data loggers.

At each wave exposure location, wave-induced flow speeds were measured for a total of 12-33 h per site over 6-10 d between June 2015 and January 2018. Paired measurements were taken at exposed and sheltered locations on each sampling day to account for temporal variation in wave height. We measured flow speeds using a SonTek Argonaut ${ }^{\circledR}$ Acoustic Doppler Velocimeter (ADV) mounted in a steel weighted frame deployed horizontally at $30 \mathrm{~cm}$ above the substrate and oriented perpendicular to the primary onshore-offshore direction of approaching waves. Instantaneous water velocity measurements were made at $10 \mathrm{~Hz}$ and averaged every $3 \mathrm{~s}$ along onshore/offshore $(x)$, along shore $(y)$, and vertical $(z)$ dimensions of flow. Data were filtered prior to calculations to remove errant extreme data points (Siddon and Witman 2003). We then calculated absolute flow speed for each 3-s interval:

$$
\sqrt{x^{2}+y^{2}+z^{2}}
$$

as a composite predictor of herbivore and algal responses to water motion at each site and wave exposure (Witman et al. 2010, Denny 2014). Flow characteristics for each site during each season were summarized as mean, standard deviation, and maximum flow speeds, as well as the 50th, 75th, and 99th percentiles of flow speeds encountered. We also calculated the flow speed return time ( $T_{n}$, in seconds) as the time interval required to observe a flow speed equal to or greater than speciesspecific thresholds of flow limitation (Denny and Gaines 1990). Return time was calculated for each site and experiment as

$$
T_{r}(f)=\frac{1}{1-P(f)}
$$

where $P(f)$ is equal to the probability of observing a flow speed less than or equal to the estimated flow speed threshold for each species. Thresholds were estimated for the flow speed that would produce a force required to dislodge an urchin, the estimated flow speed required to prevent feeding by an urchin (Kawamata 1998, Siddon and Witman 2003), and the maximum sustained swimming speeds for each fish family (Fulton 2007). Wave speeds necessary to dislodge an E. galapagensis urchin were calculated based on mean urchin test diameter from this study and using the drag and lift equations and the predicted dislodgement force for E. galapagensis of $11.98 \mathrm{~N}$ reported in Brandt (2012; Appendix S1: Table S1).

\section{Environmental filtering along a wave-exposure gradient}

To test hypotheses 1 and 2 (Table 1) we quantified populations of herbivores and benthic algal and sessile invertebrate communities on shallow rocky reefs (7-10-m depth) at each site in relation to wave exposure levels. We surveyed benthic communities along $30 \times 5 \mathrm{~m}$ band transects running parallel to shore. We performed 6-7 transects per location between July 2015 and July 2017 by selecting starting points haphazardly within the study area and swimming a meter tape parallel to shore at a constant depth. We used a random number generator to select the location of 12 quadrat images $\left(0.25 \mathrm{~m}^{2}\right.$; 24megapixel resolution) of the benthos taken along the 30$\mathrm{m}$ tape using a quadrapod camera frame (Witman et al. 2004). Percent cover of sessile organisms was quantified by evaluating each quadrat image on a computer screen by overlaying a digital layer of 200 randomly distributed points. Algae and benthic invertebrates under each contact point were visually identified to the lowest taxonomic unit possible and tallied to establish percent cover.

We also counted E. galapagensis pencil urchins, which was the only species of sea urchin observed at any of the experimental sites in the quadrat images. Pencil urchins have few tube feet and relatively weak attachment strength, and instead use their thick, strong spines to wedge themselves into cracks and under rocks (Brandt and Guarderas 2002). This is a common deterrent to predators (Dee et al. 2012, Witman et al. 2017), but we also considered it a refuge-seeking behavior indicative of potential risk of dislodgement by waves. While assessing the abundance of organisms along transects, we also estimated the proportion of all urchins that were in refuges by attempting to lift each urchin off the substrate manually ( $n=1,611-2,227$ urchins per location). If we were able to lift the urchin off the substrate with no resistance, it was labeled as "non-refuge," and the distance to the nearest suitable refuge (a crack or overhanging rock of suitable size) was measured using a meter tape. If it was 
wedged into a crevice or among boulders and was difficult to dislodge, it was labeled as "refuge."

We measured the speed with which urchins can move over the substrate to reach a refuge from extreme flow speeds by first placing an urchin on a flat area of rock outlined with meter tape, with a GoPro ${ }^{\circledR}$ camera facing straight downwards on a 1.5 -m-tall tripod. Images were taken at 2-s intervals, and the procedure was repeated for 41 urchins. We visually quantified the displacement (number of body lengths) of each urchin during a 20min observation period in the time-lapse images, multiplied by the test diameter of the urchin to obtain speed in centimeters per second.

We censused reef fish biomass by counting all fish along the same transects as benthic communities. Along each transect and extending from the benthos to the ocean surface, fish were counted, identified to species, and a visual estimate was made of their size. Sizes were only estimated by R. W. Lamb to minimize bias. Fish total lengths were converted to biomass using a conversion formula from length $(\mathrm{cm})$ to weight $(\mathrm{g})$ :

$$
W=a L^{b}
$$

where $W$ is fish weight in grams, $L$ is fish total length (length from the tip of the snout to the tip of the caudal fin) in centimeters, and $a$ and $b$ are species constants describing mass increase with length (Froese and Pauly 2019). Biomass was then pooled within taxonomic families for analysis based on similar swimming performance among species within each family in high wave conditions (Fulton and Bellwood 2005).

\section{Rates of herbivory along a wave exposure gradient}

We conducted two types of experiments to test hypotheses 3 and 4 (Table 1). The first experiment was a standardized algal feeding assay designed to quantify the capacity for herbivorous fishes and urchins to feed at each location. We created standardized algal assays by sandwiching pre-weighed clumps of Ulva spp. between two $5 \times 8 \mathrm{~cm}$ strips of plastic-coated wire mesh $(10-\mathrm{mm}$ gauge, Aquamesh $\AA$, Riverdale Mills, Northbridge, Massachusetts, USA). Cable ties were used to close the Aquamesh at either end. This held the algae firmly in place even under strong flow conditions, and the large $2.5-\mathrm{cm}$-wide openings in the mesh allowed pieces of algae to protrude, providing feeding access to herbivores. Each algal clump was vigorously dried in a salad spinner to remove excess water, blotted with tissue paper, and weighed prior to deployment for starting damp biomass. Each preweighed algal "sandwich" (Appendix S1: Fig. S2) was then transported underwater in a plastic bag and cable tied to a $2-\mathrm{kg}$ lead weight.

We deployed Ulva sandwiches on the exposed and sheltered rocky reefs at Caamaño and Palmas in cages designed to exclude different herbivore groups selectively.
Exclusion cages made out of Aquamesh were bolted to the rock using stainless steel anchors and bolts set in the rock with a pneumatic drill (Chicago Pneumatic ${ }^{\circledR}$ CP9A rotary hammer) run off of the air pressure in a scuba tank. This enabled us to set up independent cages randomly spread over an approximately $50 \times 30 \mathrm{~m}$ area of the rocky sea floor at 7-10-m depth at each of the four locations. Cages were circular, covered a rock surface of $0.25 \mathrm{~m}^{2}$, and were $15 \mathrm{~cm}$ high. The four treatments included: + all consumers (allowing access to both fish and urchins) in which the sandwich was bolted directly to the rocky reef with no cage; - all consumers (limiting access to both fish and urchins), which consisted of a circular fence and mesh roof surrounding the sandwich in a full exclusion cage; + fish (limiting access to urchins), which was the full exclusion cage with the roof removed and the top $5 \mathrm{~cm}$ of the cage bent outwards at a $90^{\circ}$ angle to prevent entry by pencil urchins (Witman et al. 2017); and + urchins (limiting access to fish), which was the full exclusion cage with holes cut in the bottom of the mesh 5-6 $\mathrm{cm}$ high by $12 \mathrm{~cm}$ wide, allowing access to urchins but limiting access to larger herbivorous fishes (Appendix S1: Fig. S2). This cage design left only three anchor points for the + urchins treatment, minimizing the shelter space available for urchin aggregation. There were six replicates of each treatment at each location. Each assay was left in its respective herbivore exclusion treatment for $5 \mathrm{~d}$. At the end of the trial, algae were returned to the lab and weighed for change in damp biomass using the same protocol as before. A single trial was performed at each location in August 2017.

Simultaneous measurement of water-flow velocities with the ADV provided a measure of differences in wave conditions among sites during each experiment. GoPro cameras (Hero models 3-5; 12 megapixel; 60 frames $/ \mathrm{s} \circledast$, GoPro Inc., San Mateo, California, USA) were set up on 1-m-tall tripods overlooking each herbivory assay to record video for $2 \mathrm{~h}$ on the first and last day of the experiments, enabling us to detect the herbivore species responsible for algal consumption. We recorded each time a fish bit an Ulva sandwich, and also monitored a $2-\mathrm{m}^{2}$ patch of rocky reef to establish baseline herbivory rates at each site ( $n=8-12$ patches per location). We simultaneously recorded bites in videos and flow speeds using the ADV within $0.25 \mathrm{~m}$ distance. These data were paired using the time stamp of video and flow data with a precision of $\pm 1.5 \mathrm{~s}$ to establish the distribution of flow speeds at which bites were taken by each species of herbivorous fish.

\section{Effects of herbivory on algal communities along a wave exposure gradient}

The second experiment was designed to test the effect of fish and urchin herbivores on the establishment and growth of benthic algae over time, or "community assembly" (Weiher and Keddy 2001). The experiment took place at the same four locations and in the same 
exclusion cages as the first experiment. To measure algal community assembly more precisely on experimental components that could be analyzed in the lab, two $13 \times 13 \mathrm{~cm}$ polycarbonate plastic plates were separated by $5 \mathrm{~cm}$ and bolted to the rock (as above) in each cage or control, at least $5 \mathrm{~cm}$ from the edge of cages in order to minimize edge effects and the tendency for pencil urchins to aggregate near shelters (Witman et al. 2017). These experiments were performed twice and ran for 2 months, with the first trial corresponding to the warm season in November 2016-January 2017 and the second during the cool season June-August 2017. The plates were left under natural conditions of algal recruitment, growth, and herbivory during these periods. The experiments were visited every $2-3$ weeks in order to remove fouling organisms and repair any wave damage to cages.

At the end of the 2-month study, all plates were photographed underwater with the quadrapod and retrieved. In the laboratory, plates were assessed for the diversity and relative abundance of benthic algae and encrusting invertebrates. An evenly spaced $10 \times 10$ plastic grid was placed over the plate. At each intersection point $(n=100)$, the type of cover was recorded to genus level. All benthic organisms were then scraped from the plate and divided into functional categories (upright macroalgae, including filamentous, foliose, and branching forms; crustose algae, both calcareous and fleshy; and sessile invertebrates). Categories were based on functional groups established in Steneck and Dethier (1994). These samples were then dried at $70^{\circ} \mathrm{C}$ for $72 \mathrm{~h}$ and weighed to attain dry biomass. Biomass data were used to examine the effects of fish and urchins on benthic algal communities as in hypotheses 3 and 4 (Table 1).

\section{Statistical analyses}

To test hypotheses 1 and 2, we first used AndersonDarling tests (Stephens 1974) to compare flow speed distributions between the four experimental locations and two seasons, with Bonferroni correction of the $P$ values for multiple comparisons. We also compared flow speed percentiles and return times for species-specific flow-tolerance thresholds for each experiment. We examined the correlation between each summary metric of flow (mean, SD, etc.) using Pearson's correlation coefficients. Percent cover data from benthic quadrats were analyzed using both multivariate and univariate statistics. Multivariate analysis involved a nonmetric multidimensional scaling analysis of a Bray-Curtis dissimilarity matrix on arc-sine square root-transformed values of proportional cover for each species. This was followed by a permutational analysis of variance (PERMANOVA) test for differences in community composition among locations, and similarity percentage analysis (SIMPER) to determine which species contributed most to differences between locations.

For univariate analysis, we grouped all crustose algal species into a "crustose" category, and grouped all upright forms of filamentous, foliose, and branching species in an "upright macroalgae" category, because of the limited precision with which we were able to separate individual organisms for weighing. We then tested for differences among sampling locations for macroalgal and crustose algal percent cover, biomass of Pomacentridae, Labridae-Scarinae, and Acanthuridae herbivorous fishes, urchin densities, and proportion of urchins hiding in refuges using one-way ANOVA and Tukey post hoc analysis for pairwise comparisons. We also used linear regression to test the effects of bulk mean flow speeds on $\log (x+1.1)$-transformed algal biomass, herbivorous fish biomass for each of the three families, and on urchin densities.

To examine the effects of flow speed on fish feeding behavior, we compared the distributions of flow speeds measured at the exact moment each bite was recorded for each species of herbivorous fish using AndersonDarling tests (with Bonferroni corrections of $P$ values for multiple comparisons). We then modeled the effects of changes in fish diversity on herbivory rates across the flow gradient by randomly selecting $1,2,3$, 4, or 5 species from all species observed feeding. The number of bites taken by each species was summed within $1-\mathrm{cm} / \mathrm{s}$ flow speed intervals, then divided by the frequency with which each flow speed measured to get bites per observation. The randomization and summation steps were repeated 100 times, and the mean bite rate at each $1-\mathrm{cm} / \mathrm{s}$ flow speed interval was averaged across iterations. We then fit LOWESS curves to the data to compare the effects of modeled richness treatments on foraging rates across the flow gradient.

To test hypotheses 3 and 4, the results from the Ulva removal herbivory experiment and the 2-month algal development experiment were analyzed using multiway analysis of variance (ANOVA) with site, exposure, and treatment as fixed, fully crossed factors. We could not statistically test the effect of season on the 2-month algal colonization experiment, because the spatial replication within and among sites during only one warm and one cool season would constitute pseudo-replication (Hurlbert 1984), so we analyzed the two trials of the experiment separately. Post hoc pairwise comparisons were performed using Tukey's honest significant difference tests. Algal biomass and herbivore abundance and biomass were $\log (x+1.1)$-transformed to meet ANOVA model assumptions.

\section{Results}

\section{Study sites and wave-induced water motion}

All study sites consisted of rocky reefs with shallow slopes and mixed substrate sizes including flat and fractured lava bedrock, large boulders, and small cobble. The distributions of wave-induced flow speeds varied between each combination of site and exposure (Anderson-Darling tests: $P<0.001$ for all pairwise 
comparisons; Appendix S1: Table S2, Fig. S3). Across sites and wave exposure locations, flow speeds were higher during the cool season than the warm season (Appendix S1: Tables S1 and S2). Across both seasons, the wave-exposed location at Caamaño exhibited the highest mean flow speeds of $37.13 \mathrm{~cm} / \mathrm{s}$ (41.42 SD), followed by Palmas exposed: $33.37 \mathrm{~cm} / \mathrm{s}$ (42.49), Palmas sheltered: $16.05 \mathrm{~cm} / \mathrm{s}(14.02)$, and Caamaño sheltered: $15.54 \mathrm{~cm} / \mathrm{s}$ (13.16). The return time for flow speeds required to restrict feeding by Eucidaris urchins was 9.3$84.2 \mathrm{~s}$ at exposed locations and 62.7-535 s at sheltered locations. Wave speeds capable of dislodging urchins were only observed at exposed locations, with a return time of 1,196-6,973 s. The return time of waves surpassing fish maximum swimming speeds ranged from 34 to $1,874 \mathrm{~s}$ at exposed locations and from 474 to $8,697 \mathrm{~s}$ at sheltered locations. Flow speed mean, SD, and all percentiles were positively correlated with each other, with correlation coefficients surpassing 0.95 in all pairwise comparisons (Appendix S1: Table S1). Subtidal water temperature was $1-2^{\circ} \mathrm{C}$ warmer during the warm season than the cool season and Caamaño was consistently 1$4^{\circ} \mathrm{C}$ warmer than Las Palmas. However, there were no significant differences in temperature between sheltered and exposed locations, and temperature was not correlated with any metric of flow speed (Appendix S1: Table S1).

\section{Environmental filtering along a wave exposure gradient}

Site differences in mean flow velocities and frequency of extreme flow speeds corresponded to consistent differences in the entire marine community (Fig. 1). Rocky reefs at locations exposed to high waves averaged $42-45 \%$ cover of benthic macroalgae, whereas sheltered locations averaged $6-20 \%\left(F_{3,48}=41.08 ; P<0.001\right.$; Fig. 1 A $)$. In contrast, sheltered locations were dominated by $60-66 \%$ cover of crustose coralline algae (CCA), in comparison to $24-29 \%$ at exposed locations $\left(F_{3,48}=51.49 ; P<0.001\right.$; Fig. 1B). Fishes were the dominant herbivore at exposed locations: there were $12-19 \mathrm{~kg} / 50 \mathrm{~m}^{2}$ of surgeonfishes and $2-9 \mathrm{~kg} / 50 \mathrm{~m}^{2}$ of parrotfishes relative to only $0.1-0.6$ and $0.5-0.6 \mathrm{~kg} / 50 \mathrm{~m}^{2}$ at sheltered sites, respectively (surgeonfish: $F_{3,73}=11.426 ; P<0.001$; Fig. $1 \mathrm{C}$; parrotfish: $F_{3,73}=5.21 ; P=0.003$; Fig. 1D). The dominant herbivore at sheltered sites was the slate pencil urchin E. galapagensis, which reached densities of 40-59 urchins $/ \mathrm{m}^{2}$, relative to $17-19$ urchins $/ \mathrm{m}^{2}$ at exposed locations $\left(F_{3,147}=33.1 ; \quad P<0.001 ;\right.$ Fig. $\left.1 \mathrm{E}\right)$. At wave-exposed locations, over $99 \%$ of urchins were in refuges, compared to only $71.5 \%$ at sheltered locations $\left(F_{3,88}=163\right.$; $P<0.001)$. The average speed of urchin movement measured using time-lapse photography over 20 -min periods on the benthos was $0.06 \mathrm{~cm} / \mathrm{s}(0.04 \mathrm{SD})$, and mean urchin size was $4.69 \mathrm{~cm}(0.72 \mathrm{SD})$. The maximum speed of urchin movement measured was $0.17 \mathrm{~cm} / \mathrm{s}$.

There was a tendency for less diverse benthic communities at sheltered locations, with an average of 5.4 (1.8
SD) algal species per $0.25 \mathrm{~m}^{2}$ at the sheltered location at Palmas and 6.3 (1.1 SD) at Caamaño, as compared to $8.8(1.3 \mathrm{SD})$ and $9.3(1.5 \mathrm{SD})$ species of algae per quadrat at exposed locations, respectively. Multivariate analysis revealed that the benthic algal community was different between exposed and sheltered locations (PERMANOVA: $\left.F_{3,48}=17.5 ; P=0.001\right)$. The primary contributors to differences between exposed and sheltered locations were Lithothamnion spp. and Hildenbrandia spp., both of which are crustose algae that were more abundant in quadrats from sheltered locations, and foliose and filamentous algae including Ulva spp., Polysiphonia spp., and Ceramium spp., all of which were more abundant in exposed location quadrats (SIMPER analysis-Appendix S1: Table S3). Several other species of upright macroalgae such as Gelidium spp., Hypnea spp., and Dictyota spp. also occurred at exposed locations although in low abundance, generating a more speciose, complex, and variable community than at sheltered locations (Appendix S1: Fig. S4).

The 2-month herbivore exclusion experiments carried out in one warm and one cool season provided added evidence for environmental filtering of each group by wave exposure. The full exclusion treatment provided a test of whether benthic algal biomass was predicted by flow in the absence of herbivores, and yielded a positive linear relationship between macroalgal biomass and mean flow speed measured across both trials of the experiment $\left(y=0.022 x-0.13 ; P=0.002 ; R^{2}=0.8\right.$; Fig. 2A). In contrast, pencil urchin abundance was negatively correlated with mean flow speed $(y=-0.015 x+$ $1.69 ; P=0.022 ; R^{2}=0.55$; Fig. 2B). Herbivorous fish biomass was in general positively correlated with mean flow speed. A positive linear relationship existed for surgeonfishes $\left(y=0.03 x-0.25 ; \quad P=0.033 ; R^{2}=0.48\right.$; Fig. 2C) and for parrotfishes $(y=0.02 x-0.09$; $P=0.016 ; R^{2}=0.59 ;$ Fig. 2D), and no significant linear or polynomial relationship existed for damselfishes, which exhibited peak biomass at intermediate flow speeds (Fig. 2E).

\section{Herbivory rates along a wave exposure gradient}

In the rapid algal feeding assay ("Ulva sandwich") experiment there was an effect of site $\left(F_{1,76}=11.56\right.$; $P=0.001)$, treatment $\left(F_{3,76}=32.35 ; P<0.001\right)$, and an interaction between site and treatment $\left(F_{3,76}=5.4\right.$; $P=0.002)$ and exposure and treatment $\left(F_{3,76}=5.52\right.$, $P=0.002$; Fig. 3; Appendix S1: Table S4). At exposed locations, there was no difference in Ulva biomass loss relative to full exclusion cages ( - all consumers) when only urchins had access to algae (+ urchins; adjusted $P=0.973)$. In contrast, sandwiches in the + fish treatment had Ulva biomass reduced three times more than the -all consumers treatment at exposed locations (adjusted $P=<0.001$ ). Assays exposed to all herbivores ( + all consumers) lost more algae than either + fish or + urchin treatments. At the sheltered locations, urchins 

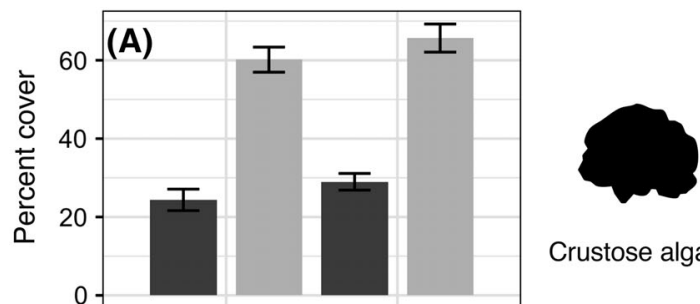

Crustose algae
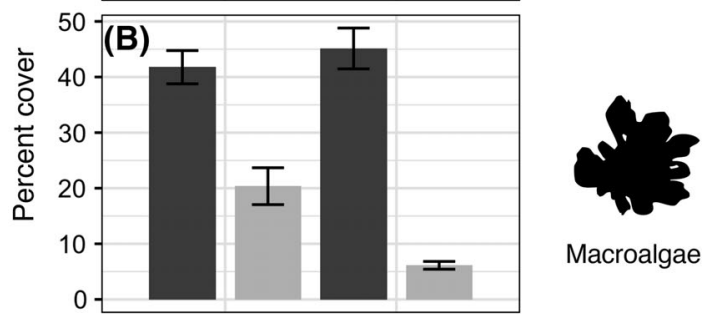

Macroalgae
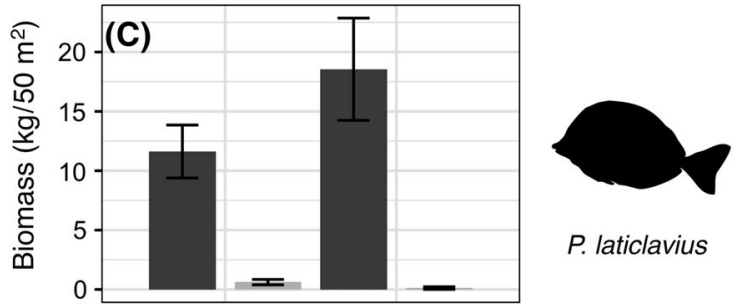

P. laticlavius
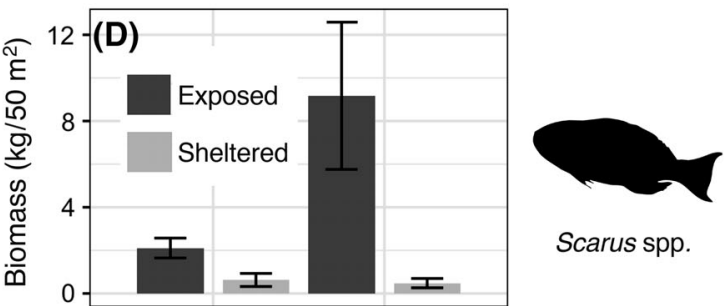

Scarus spp.
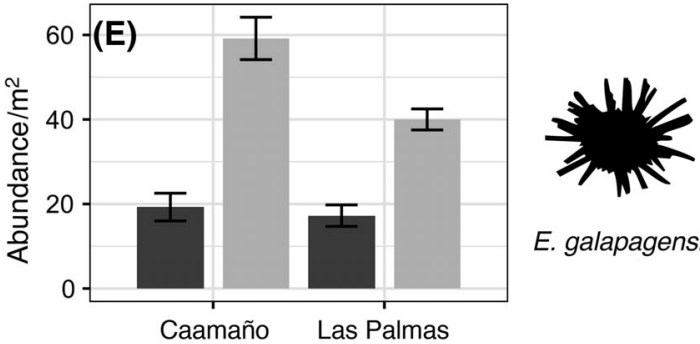

E. galapagensis

FIG. 1. Abundance of benthic organisms and herbivores at wave-sheltered (light gray) and exposed (dark gray) experimental sites. $y$-axes correspond to proportion of total cover for crustose coralline algae (CCA-Lithothamnion spp.) and macroalgae (primarily Ulva spp., Ceramium spp., Hypnea spp., Polysiphonia spp.), biomass (per $50 \mathrm{~m}^{2}$ ) for parrotfishes (Scarus spp.), damselfishes (Stegastes spp., Microspathodon dorsalis) and surgeonfish (Prionurus laticlavius), and density $\left(\right.$ per $\mathrm{m}^{2}$ ) for sea urchins (Eucidaris galapagensis). Values shown are mean and standard error.

removed nearly $100 \%$ of Ulva biomass (adjusted $P<0.001$ ), as also occurred in the + all consumer treatment (adjusted $P<0.001$ ). Fish grazers alone also reduced algal biomass at sheltered locations (adjusted $P<0.001)$ although they were less effective at consuming algae than urchins in low-flow velocities, a difference that was not significant (adjusted $P=0.325$ ).

\section{Effects of herbivory on algal communities along a wave exposure gradient}

The two deployments of the 2-month algal community assembly experiment during one warm and one cool season produced very similar effects of each herbivore exclusion treatment on the biomass of benthic macroalgae. However, the direct effect of greater flow speeds and colder, likely more productive waters on algal biomass during the cool season was also apparent. Mean biomass was 2-5 times higher across all treatments during the cool season than the warm season. Across both seasons, the all consumers (total herbivore exclusion) treatment at the exposed locations developed 3-20 times greater biomass than the corresponding treatment at sheltered locations.

At both exposed locations and during both trials, there was no significant difference in macroalgal biomass between the -all consumers (full exclusion) and the + urchin treatment (Fig. 4). This follows the predictions of the ESH by showing that urchin grazing is severely reduced at high wave exposure. In contrast, at Caamaño exposed, macroalgal biomass in the + fish treatment was reduced by an average $65 \%$ relative to the - all consumers treatment in the warm season (adjusted $P=0.006$ ) and by $91 \%$ in the cool season (adjusted $P<0.001$ ), indicating that fish were capable of reducing macroalgal biomass despite the high exposure to waves (Appendix S1: Table S5: ANOVA and Tukey post hoc tests). However, this difference was not significant at Las Palmas during either season. Assays exposed to all herbivores ( + all consumers) yielded lower algal biomass than either + fish or + urchin treatments.

At sheltered locations, both + fish and + urchin treatments resulted in lower biomass than the - all consumers treatment, indicating grazing effects of both herbivore guilds in this more benign environment. However, on average fish herbivory reduced macroalgal biomass by approximately $70 \%$ relative to the full exclusion cage treatment, whereas the urchin inclusion reduced algal biomass by $87 \%$, indicating a greater capacity for urchin grazing than fish at sheltered locations. The open controls that allowed access to both guilds of herbivores similarly exhibited an $85 \%$ reduction in macroalgal biomass, and there was no significant difference between the urchin inclusion and open controls for either sheltered location or season. The trial at Las Palmas sheltered location during the warm season produced such low biomass of algae, even in the full exclusion cages, that there were no significant differences between any of the treatments.

Analysis of stationary video deployed at each site to measure fish herbivory rates detected a total of 17 species feeding on the benthos (Appendix S1: Table S6). Herbivory rates were $1-3$ orders of magnitude higher at the two exposed locations, where Prionurus laticlavius 


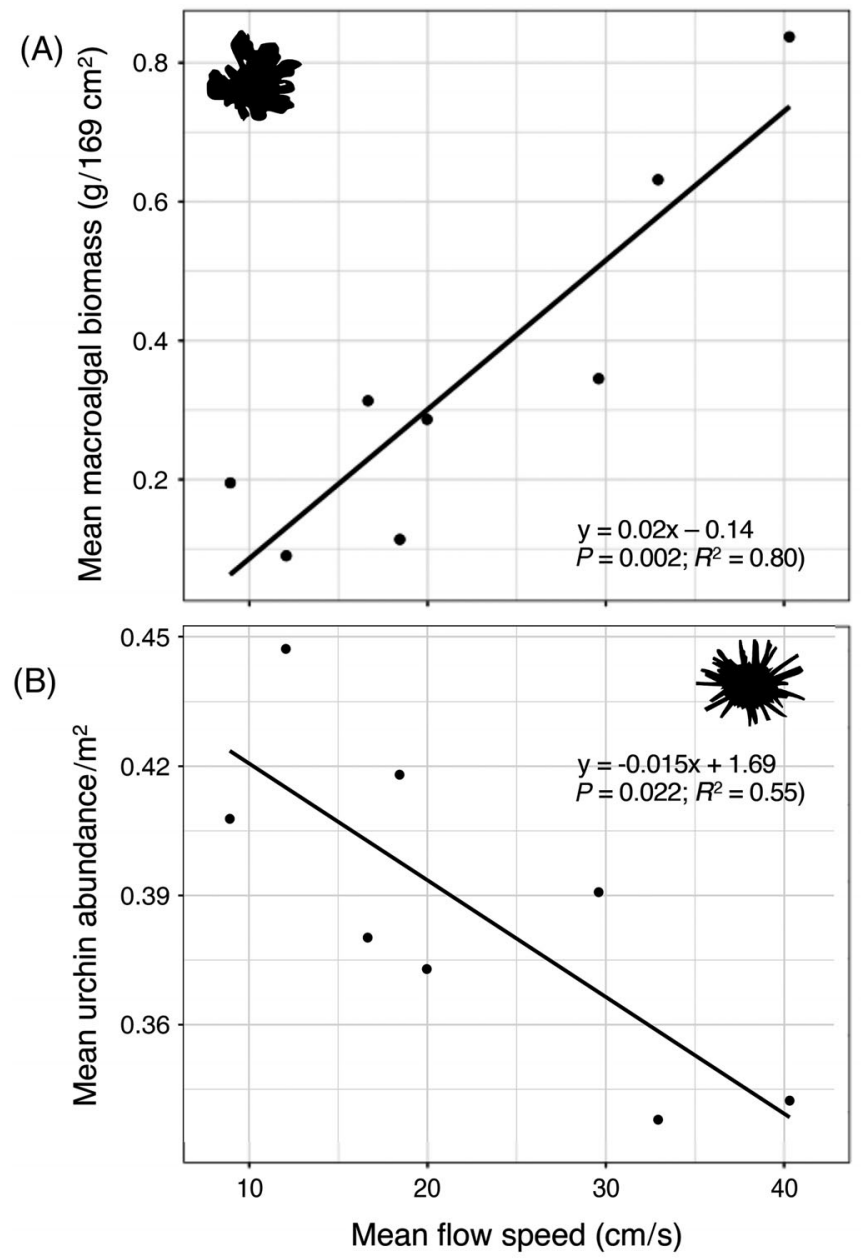

(C)

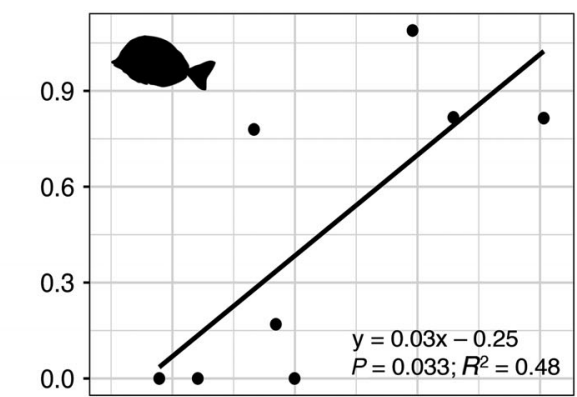

(D)

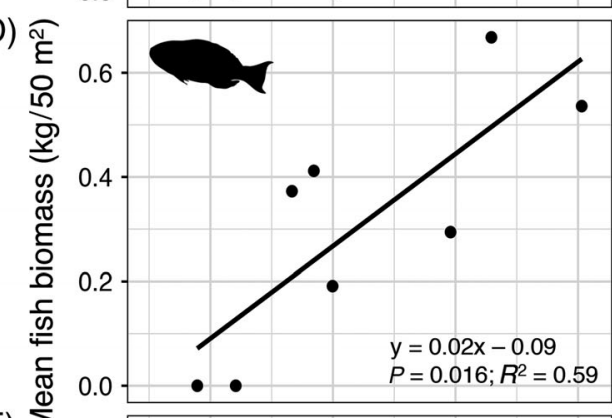

(E)

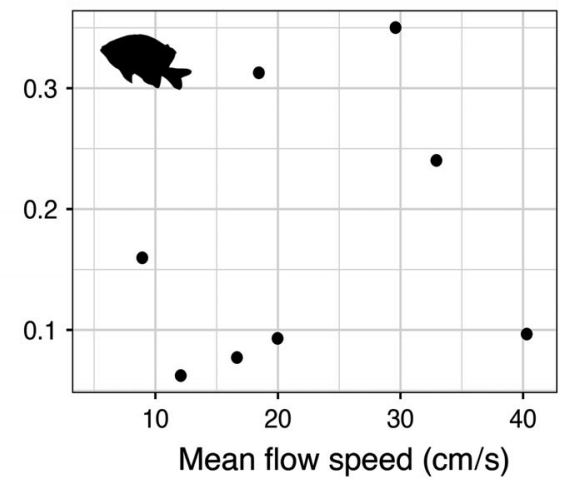

FIG. 2. Linear regression analysis of algae and herbivore biomass and abundance against mean flow velocities measured in situ at experimental sites. Each point on the $x$-axis represents the mean flow speed measured during the course of a 2-month herbivore exclusion experiment ( $n=4,149-28,494$ measurements per site and date). The $y$-axis represents (A) mean macroalgal biomass per $169 \mathrm{~cm}^{2}$ from experimental plates at each site during each trial of the experiment ( $n=12$ plates per location/trial); (B) mean abundance per $\mathrm{m}^{2}$ of Eucidaris galapagensis urchins, and mean fish biomass per $50-\mathrm{m}^{2}$ transect for (C) Acanthuridae (surgeonfishes); (D) Labridae-Scarinae (parrotfishes); and (E) Pomacentridae (damselfishes). All biomass and abundance data are $\log (x+1)-\operatorname{trans}-$ formed to meet linear model assumptions.

(razor surgeonfish) was the most important species by far, recording $6.1(9.22 \mathrm{SD})$ bites per minute per $2 \mathrm{~m}^{2}$ at Palmas exposed and 79.2 (120.0) bites per minute per $2 \mathrm{~m}^{2}$ at Caamaño exposed. The labrid Thalassoma lucasanum also fed primarily at exposed locations. Bites by damselfishes (Stegastes arcifrons, S. beebei, Microspathodon dorsalis) and parrotfishes (Scarus spp.) were more evenly distributed across sheltered and exposed locations. Simultaneous ADV measurements revealed how the foraging rates by each species were affected by waveinduced flow speeds (Fig. 5A). Three distinct feeding groups were revealed by Anderson-Darling tests of the distribution of flow speeds measured when bites were taken (Fig. 5A, Appendix S1: Table S7). The razor surgeonfish ( $P$. laticlavius), Panamic fanged blenny
(Ophioblennius steindachneri), giant damselfish (M. dorsalis), and rainbow wrasse (T. lucasanum) were the most important grazers at high flow speeds. In contrast, ringtail damselfish (S. beebei), yellowtail damselfish (S. arcifrons), chameleon wrasse (Halichoeres dispilus), and parrotfishes (Scarus spp.) focused their feeding efforts at low flow speeds. A third group of intermediate flow speed feeders was composed of the king angelfish (Holacanthus passer) and spinster wrasse (Halichoeres nicholsi). Modeling the effect of species richness on herbivory rates revealed that higher species richness resulted in greater herbivory rates per observation across the flow speed gradient, but that the magnitude of the richness effect was greatest between approximately 40 and $120 \mathrm{~cm} / \mathrm{s}$ (Fig. 5B). 
Exposed

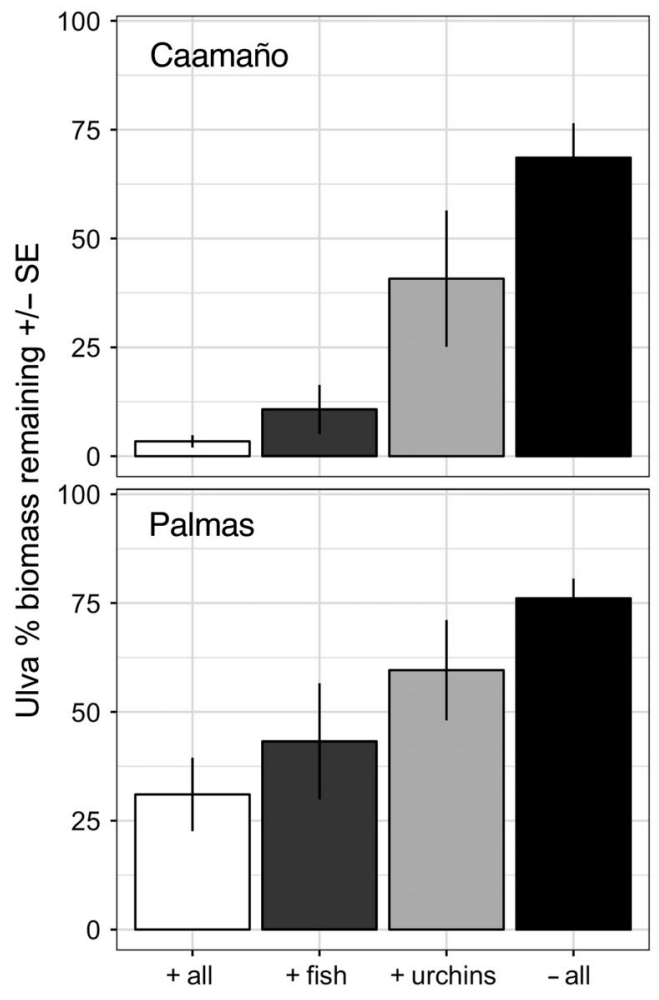

Sheltered

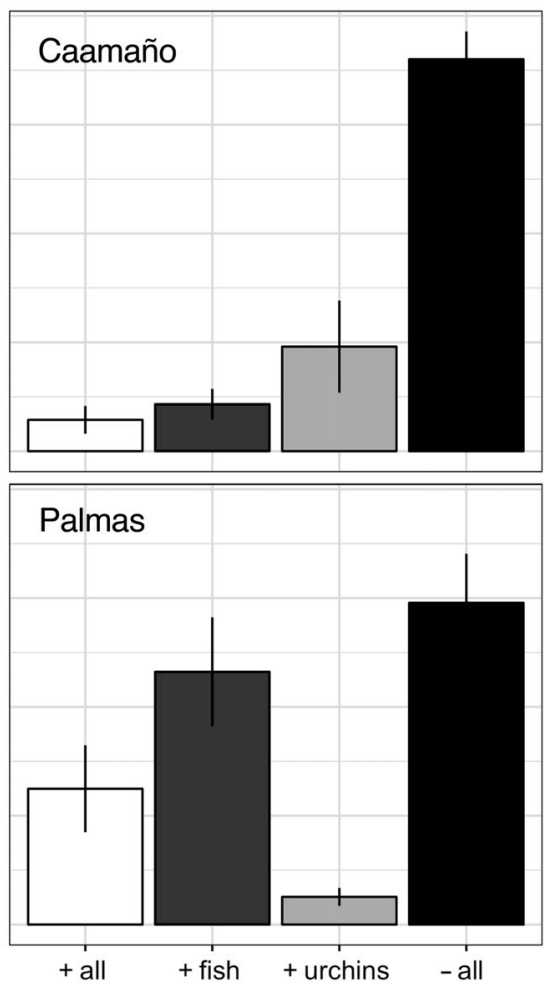

FIG. 3. Percent of Ulva sp. biomass remaining after a 5-d experiment using preweighed algal assays. Effects of all herbivores (white), urchins (dark gray), fish (light gray) and no herbivores (black) on preweighed algal assays of Ulva sp. This palatable foliose green alga was pinned between pieces of Aquamesh in a "sandwich," allowing herbivore access between the 2.5-cm holes in the mesh. The percent Ulva biomass remaining was measured after $5 \mathrm{~d}$ as an indication of the grazing rates of each guild of herbivores. Values shown are mean and standard error ( $n=6$ replicates per treatment).

\section{Discussion}

Our study partitioned several of the dominant direct and indirect effects of wave-induced water motion on consumers (fish and urchins) and their basal resource (benthic algae). By quantifying the effects of consumer foraging rates across an environmental gradient based on consumer mobility, we present a novel test of the ESH (Menge and Sutherland 1976, 1987). Both shortterm grazing assays and longer-term community assembly experiments showed that the dominant herbivore guild switched between urchins in low-flow habitats and fish in high flow habitats (Fig. 6A). This pronounced switching of dominant herbivore guilds is likely due to a combination of factors, including the availability of optimal food resources, return time of limiting speciesspecific flow speeds, and the ability of each species to access available resources within the return time window. We have described a behavioral mechanism by which highly mobile animals (such as fishes) can exit a resource patch when stress is high and return to feed when stress is low. In contrast, relatively slow animals (such as urchins) are restricted to resource patches where the return time of limiting stress is comparatively longer.
Consequently, we propose an extension of the ESH, contingent upon consumer mobility relative to the return time of environmental stress, for predicting foraging rates and consumer effects on basal organisms across environmental gradients (Fig. 6B). We suggest that this phenomenon is widespread in other ecosystems. For example, gulls access briefly available marine food resources by feeding on intertidal invertebrates at low tide and between sets of crashing waves (Irons et al. 1986, Ellis et al. 2007). In response to periods of extreme drought in the African savanna, megaherbivores can migrate to drought refugia, whereas smaller mixed feeders cannot (Abraham et al. 2019). Near acidic $\mathrm{CO}_{2}$ seeps in the Mediterranean, abundant benthic algae grows in the absence of grazing effects from urchins, which are excluded because of their slow movement, providing a rich food resource to herbivorous fishes, which can enter, feed, and exit before suffering negative effects (Baggini et al. 2015). Migratory African birds utilize sporadically abundant resources and are faster in both movement and foraging rates than resident species (Leisler 1992). Our study and these examples suggest that more mobile species have a foraging advantage in rapidly changing environmental conditions. Further research on the 


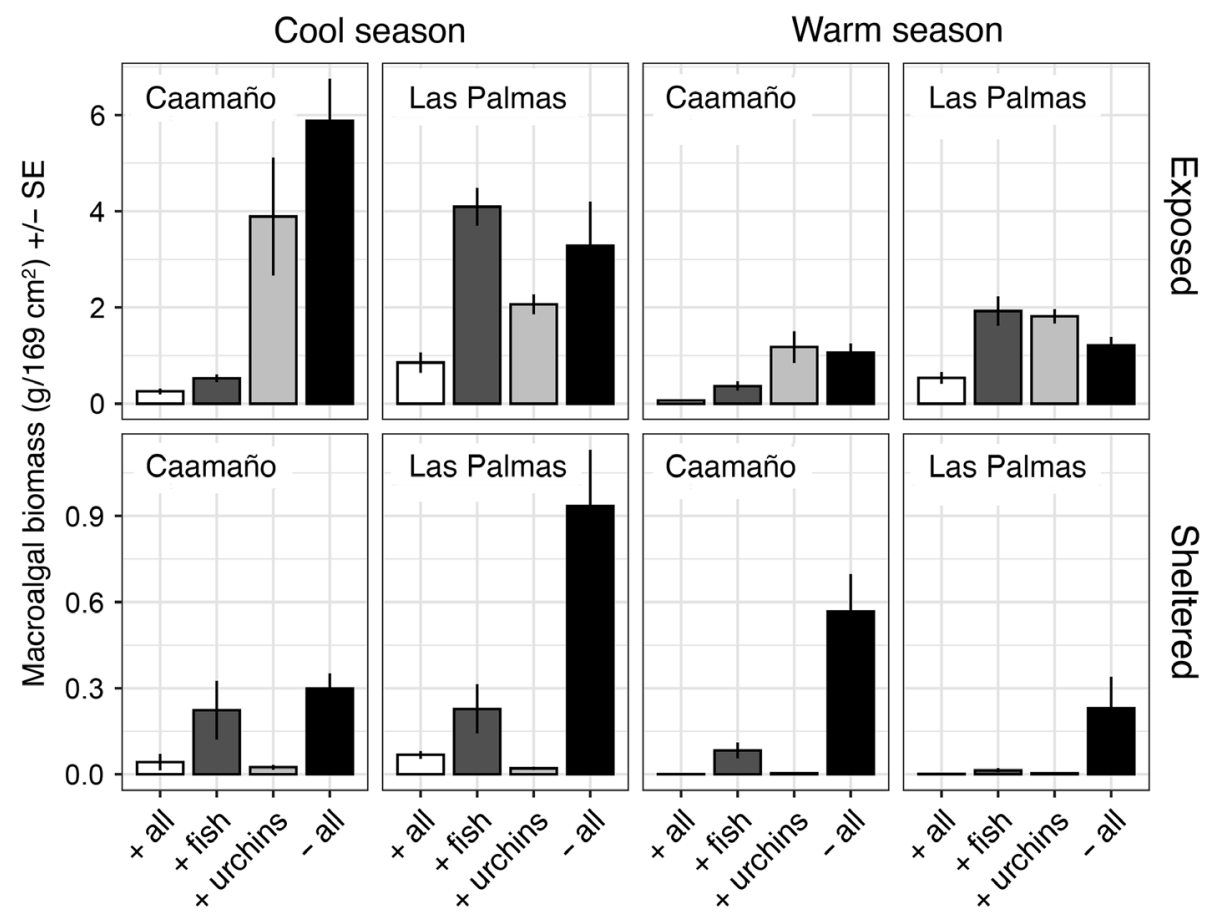

FIG. 4. Effects of herbivores on algal community assembly. Effects of all herbivores (+ all consumers, white), urchins (dark gray), fish (light gray) and no herbivores (- all consumers, black) on macroalgal biomass (combined functional groups of filamentous, foliose, and branching algae) after 2-month herbivore exclusion experiments during one warm season (November 2016January 2017) and one cool season (June-August 2017). Means and standard errors are displayed ( $n=6$ replicates per treatment). Note range of $y$-axis varies by exposure.

trait-based contingency of the ESH could focus on the quality of food resources that would justify the energetic cost of moving between habitats (Nathan et al. 2008).

There was also considerable variation in the range of flow speeds across which herbivorous fishes were observed feeding, alluding to the extremely high functional diversity (Stuart-Smith et al. 2013) and strong species identity effects (Witman et al. 2017) of herbivores in the Galapagos Islands. The mechanical limitations to herbivore feeding are dictated by the probability of encountering a wave of specific hydrodynamic parameters that would produce dislodgement or breakage (Denny et al. 1985) or that would reduce foraging by requiring animals to cling to rocks or seek refuges rather than feed (Siddon and Witman 2003, Tuya et al. 2007). Therefore, it is likely that the cumulative role of herbivores in structuring benthic algal communities on rocky subtidal reefs is dependent on the frequency of occurrence of flow speeds that surpass species-specific thresholds (Denny and Gaines 1990, Witman and Dayton 2001). Variations in the magnitude and timing of flow speeds likely combine with other environmental factors such as temperature (Carr et al. 2018) and $\mathrm{pH}$ (Baggini et al. 2015) to present a dynamic patchwork of stressful and benign conditions that foraging animals must contend with. In this context, a more diverse community would likely include species with greater tolerance limits and/or mobility, which can better facilitate the maintenance of important ecological processes such as primary production and predation along environmental stress gradients than depauperate communities (Steudel et al. 2012). We explicitly modeled the relationship between herbivore richness and foraging across a wave exposure gradient using observations of bites on the substrate along with simultaneous measurements of wave-induced flow speeds. Notably, this model revealed that the effect of consumer richness on foraging is relatively low at flow speeds $<40 \mathrm{~cm} / \mathrm{s}$ (where no species are excluded and multiple herbivore species may be redundant), increases from 40 to $120 \mathrm{~cm} / \mathrm{s}$ (where ecological complementarity may be important or strong species identity effects may occur), and then decreases at extreme flow speeds $>120 \mathrm{~cm} / \mathrm{s}$ (where all species are excluded). These results imply that diverse consumer guilds may be more resilient to moderate environmental change (Oliver et al. 2015).

There was considerable support that wave-induced water motion is as an important environmental gradient that directly influences the composition and relative abundance of species in subtidal communities. Flow speed was a strong predictor of algal biomass even in the absence of herbivores, as evidenced both by linear regression and the fact that wave-exposed herbivore exclusion treatments yielded higher biomass than the exclusion 
(A)

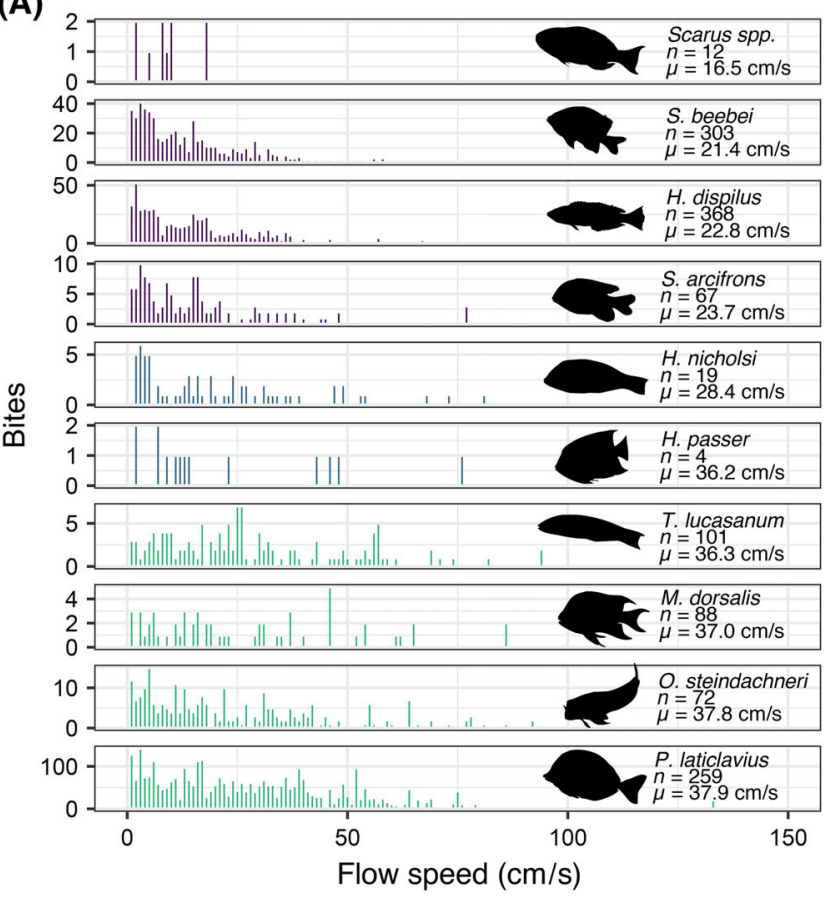

(B)

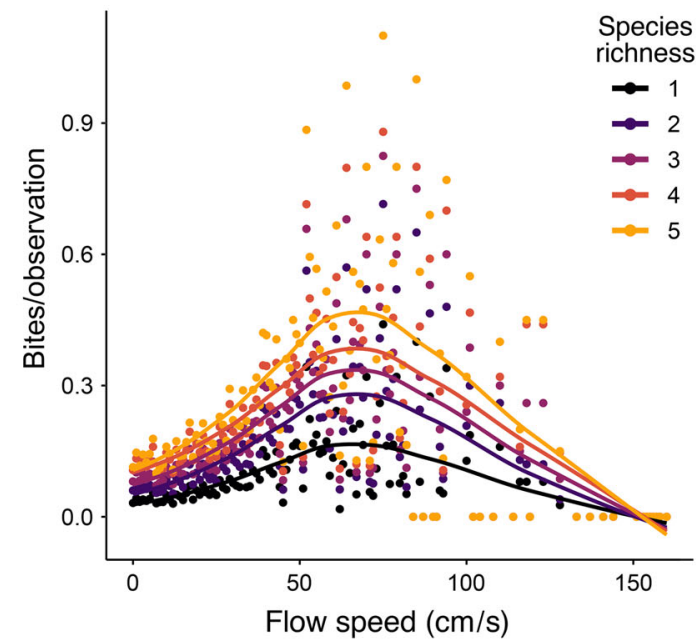

FIG. 5. Distribution of the number of bites made on natural substrata at the study sites by 10 species of herbivorous fishes across a range of flow speeds measured at the same time that bites were taken. (A) Flow speeds were measured in three dimensions (onshore-offshore, vertical, and along shore) using a Sontek Argonaut ${ }^{\circledR}$ acoustic Doppler velocimeter at $10 \mathrm{~Hz}$ and averaged over 3 -s intervals. These dimensional measurements were used to create a composite 3D flow speed in the form of $\left(x^{2}+y^{2}+z^{2}\right)^{1 / 2}$. Species were grouped based on Anderson-Darling tests for differences in flow speed distributions into high-flow (green), midflow (blue), and low-flow (purple) feeding species. $n=$ number of unique individuals observed feeding, $\mu=$ mean composite 3D flow speed at which bites were taken. Note that range of $y$-axis varies by plot. (B) Modeled effects of fish diversity (richness $=1-5$ species of herbivorous fishes) on foraging capacity across a flow speed gradient. Data from plot A were randomized and then 1-5 species were selected, summing their observed bites for each $1-\mathrm{cm} / \mathrm{s}$ interval. These steps were repeated 100 times, and the average bite rate for each flow speed interval and richness treatment was plotted. LOWESS smoother lines show the relationship between flow speed and bite rate for each treatment.

cages at the corresponding sheltered locations. The single exception of Caamaño during the cool season is likely because high flow speeds were generated by waves even at the Caamaño sheltered location during this particularly stormy period. Enhanced flow speeds at wave-exposed locations can increase benthic algal production in both intertidal (Leigh et al. 1987) and subtidal ecosystems (Burrows 2012). The primary mechanism is increased mass transfer of inorganic carbon and nutrients (namely nitrogen and phosphorous) to the surface of algal blades (Hurd 2000). We also observed higher algal biomass across treatments in the cool season than in the warm season, which is consistent with other reports from shallow subtidal rocky reefs in the Galapagos (Carr et al. 2018). This was likely because of the combined effects of upwelling of colder, more nutrient-rich water and high waves during the cool season (Houvenaghel 1978). These environmental factors and their direct effects on algal growth alone could explain a substantial proportion of the differences in standing macroalgal cover between exposed and sheltered locations (Leigh et al. 1987, Hurd 2000, Aquilino et al. 2009).
Mean flow speed was negatively correlated with urchin abundance, indicating environmental filtering as suggested by the slow rates of movement measured for $E$. galapagensis and the poor attachment strength of this species (Brandt 2012). In contrast, fish biomass for some families was positively related to in situ ADV measurements of wave exposure, as has been observed elsewhere using a wave-theory GIS approach (Bejarano et al. 2017). This suggests that many fish species are not prevented from foraging by high-frequency extreme flow speeds, and highlights wave-induced water motion as a unique environmental dimension that partitions the ecological niches of marine animals. Fulton (2007) lists mean (maximum values in parentheses) swimming speeds observed in the field of $60(76) \mathrm{cm} / \mathrm{s}$ for Acanthuridae, $52(83) \mathrm{cm} / \mathrm{s}$ for Labridae, and $49(69) \mathrm{cm} / \mathrm{s}$ for Pomacentridae. Notably, Acanthuridae (surgeonfishes), which are pectoral fin swimmers with the fastest swimming speeds among reef fishes, exhibited the strongest positive relationship with wave exposure in terms of both biomass and benthic foraging. This was also the species observed feeding at the highest flow speeds, with 
(A)
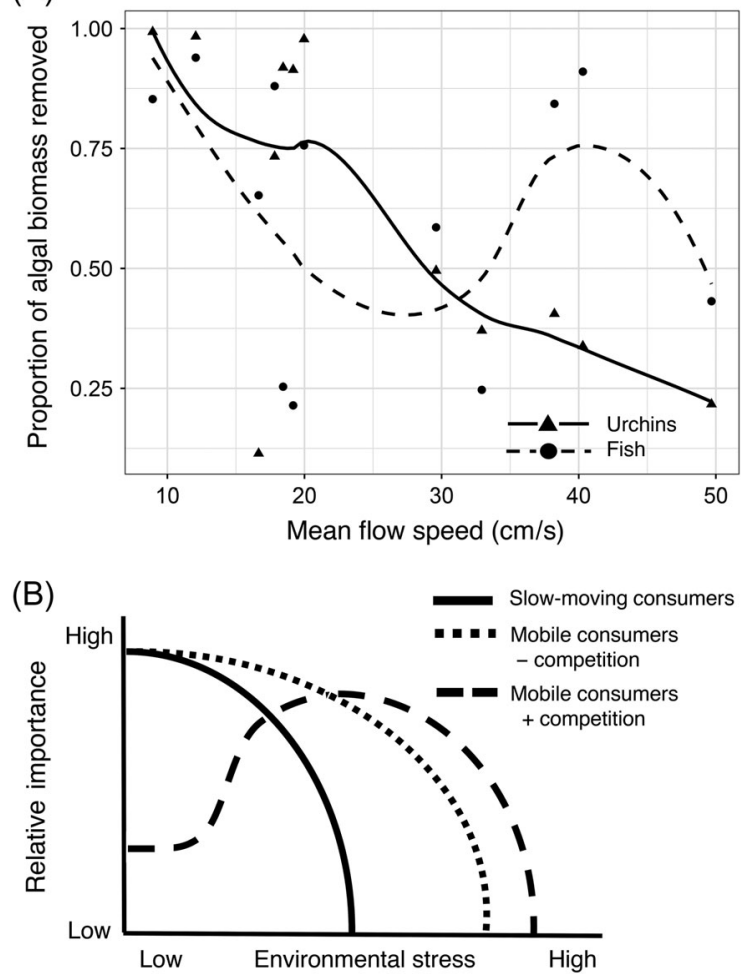

FIG. 6. Relationship between consumer impact and environmental stress. (A) Variation in the proportion of algal biomass removal relative to all herbivore exclusion treatment $\left(\operatorname{mean}_{\text {control }}-\operatorname{mean}_{\text {consumer }} / \mathrm{mean}_{\text {control }}\right)$ as predicted by mean flow speed measured over the course of the respective trial. Plot shows combined results of 2-month community assembly experiments (one trial each during one cool and one warm season) and 5-d Ulva spp. removal assays, with each point corresponding to a value between 0 (no effect of that species) and 1 (complete biomass removal relative to control). LOWESS smoothing lines were applied for each consumer group (urchins, fish). (B) "Stress-mobility" model predicting the impact of highly mobile vs. slow-moving consumer species on basal communities along an environmental stress gradient. Slow species (solid line) follow the classic environmental stress hypothesis model of reduced foraging at intermediate-high environmental stress. In contrast, mobile species (dotted line) can feed at higher environmental stress. If mobile species are in competition for basal resources with slower species (dashed line), they would be expected to avoid low-stress areas and focus their foraging at high-stress areas where slower species are excluded and resources are more abundant.

bites regularly occurring even when water motion was greater than the reported maximum swimming speeds. In contrast, whereas Labridae-Scarinae (parrotfish) biomass also showed a positive relationship with flow, Scarus spp. fed at the lowest flow speeds. This may be because parrotfishes are less reliant on the macroalgae that were only found at exposed locations (Choat et al. 2002), or that they experience greater hydrodynamic forces when feeding than surgeonfish (Liao 2007). Surgeonfish position their bodies to face directly into oncoming waves while feeding (Video S1), and their slender, disc-shaped body plan could minimize drag while feeding in high flow relative to the comparatively broad-bodied, torpedo-shaped parrotfishes (Walters 1962). Some families (Pomacentridae, Labridae) exhibited within-family variation in flow associations, which is likely an indication of niche partitioning mediated by swimming ability, feeding performance in high flows, and availability of preferred food types across a wave exposure gradient (Floeter et al. 2007). This hydrodynamic complementarity could be an important feature of the functional diversity of reef fish communities (Bejarano et al. 2017, Steneck et al. 2017).

Several lines of evidence support hypothesis $3 b$ (a mobility-contingent ESH) as our results indicate that environmental stress does not limit foraging rates, and thus capacity for control of benthic communities, for all consumer species equally. The results from both trials of the 2-month herbivore exclusion experiment at Caamaño and the results of the standardized herbivory assays using Ulva from both sites showed that herbivorous fishes are capable of reducing algal biomass even at extreme high wave exposure. Observations of fish feeding behavior revealed the mechanism for overcoming this environmental stress: many species such as $P$. laticlavius and $M$. dorsalis remain several meters above the rocky reef during peak flow speeds as a wave crashes against the shore, then dart down to the benthos to take several quick bites during the lull between waves (Video S1). The ability to move in three dimensions allows fish such as $P$. laticlavius to escape the danger of a wave knocking them against the reef by moving only a short distance. Ophioblennius steindachneri is an herbivorous blenny that apparently avoids extreme flow speeds by living in the boundary layer directly on the benthos, and taking refuge under rocks during extreme periods of high waves. However, extreme wave-induced flow speeds, which commonly surpassed maximum swimming speeds for all herbivorous fish species at exposed locations, still signify a stressor to fishes by reducing their ability to bite benthic algae (Figs. 5 and 6A). Yet the return time of these flow speeds was always longer than $9 \mathrm{~s}$, more than enough time for fish to select a patch of algae for feeding, descend to the reef, and take a bite before the next extreme flow speed was encountered (Video S1). In contrast, pencil urchins are limited to navigating in two dimensions and must remain attached to the benthos. Almost all urchins remained in cracks and crevices at exposed locations in all experiments, suggesting that they were unable to forage on substrates outside of refuges in these habitats. We also dove on the experiment at night, when urchins are more active (Brandt and Guarderas 2002, Dee et al. 2012), and observed no urchins grazing beyond $15 \mathrm{~cm}$ from the nearest refuge in exposed locations. With a maximum speed of movement over the substrate of only $0.17 \mathrm{~cm} / \mathrm{s}$, we suggest that urchins move too slowly to emerge from crevices (spatial refuges from flow) to forage and then find a new refuge before the next wave hits and flow speeds surpass their 
critical threshold. Despite the fact that flow speeds rarely reached the threshold necessary to dislodge an urchin, chronic water movement below $40 \mathrm{~cm} / \mathrm{s}$ is sufficient to reduce urchin foraging (Siddon and Witman 2003, Tuya and Haroun 2006) or prevent it entirely (Kawamata 1998).

Hypothesis 4 was also supported, because 2-month exclusion experiments showed that urchin and fish effects on benthic algal communities varied across the wave-exposure gradient. Fish effects on macroalgae were always weaker than urchin effects at sheltered locations, but tended to be stronger than urchin effects at exposed locations. The combined effect of fish and urchins in the + all consumers treatment was almost always greater than the individual effects of fish or urchins, suggesting synergistic effects of herbivory by both guilds on benthic algae. Despite fish grazing rates that surpassed 120,000 bites per $\mathrm{m}^{2}$ per day, benthic algal communities at exposed locations were diverse and characterized by abundant macroalgae. This was likely largely because of the higher production associated with high flow rates observed in our study and others (Hurd 2000) and relatively weak effects of fish grazing such as occurred at the wave-exposed location at Las Palmas. Weak effects of fish on benthic algal development at Las Palmas exposed could be explained by several factors. This location is closer to the major upwelling center in the western archipelago than Caamaño (Houvenaghel 1978), which may have overwhelmed herbivore effects through enhanced primary production. Herbivore effects tend to be weaker than nutrient-enrichment effects in highproductivity systems such as the Galapagos (Burkepile and Hay 2006). In the context of the mobility-contingent $\mathrm{ESH}$, the greater availability of algal food in this region may have relaxed the need for fish to feed in extreme wave-exposed locations, reducing the energetic cost of foraging. In addition, the most abundant fish at Las Palmas was $S$. beebei, a territorial gardener that promotes algal growth (Irving and Witman 2009).

Fish also generally create less of a disturbance to benthic algal communities when they feed than urchins do (Carpenter 1986, Morrison 1988). Tropical lineages of herbivorous fishes such as those native to Galapagos vary in the depth of algal morphology removed due to grazing (cropped blades, blades and stems/stipes, holdfast, and underlying substrata), but in general show a pattern of diffuse feeding, taking several bites from one location before moving to another (Burkepile and Hay 2008, Steneck et al. 2017). In contrast, pencil urchins tend to forage in small patches of reef where they scrape away the entire algal structure, even consuming sessile invertebrates such as corals and boring down to bare rock (Glynn et al. 1979). In dense aggregations, urchins form grazing fronts that produce extensive urchin barrens throughout the Galapagos Islands, a phenomenon previously attributed to the reduction of urchin predators by fishing (Edgar et al. 2010). However, recent experiments have shown that these urchins are under heavy predation at some sites by several species of triggerfish (Balistes polylepis and Pseudobalistes naufragium) and hogfish (Bodianus diplotaenia; Witman et al. 2017), as well as at least one species of sea star, Pentaceraster cumingi (Dee et al. 2012), raising the question as to what other local factors influence the spread of urchins and urchin barrens. Wave-exposed locations had consistently higher macroalgal cover despite urchin densities 6-7 times greater than the threshold suggested for the formation of urchin barrens (Edgar et al. 2010), suggesting that the formation of urchin barrens in the Galapagos is restricted by wave exposure.

Despite the fact that herbivorous fishes can feed even in high flow velocities, it is likely that there is an added energetic cost to swimming in these locations (Fulton and Bellwood 2005). As such, the fact that benthic macroalgae is more abundant at exposed locations may present a nutritional benefit that outweighs the metabolic demands of swimming in extreme wave-exposed environments. A greater reward in terms of higher (macroalgal) prey density relative to the increased physiological stress incurred by foraging is likely the cause of greater densities of herbivorous fishes at exposed locations (Dahlhoff et al. 2001). The fish species that concentrated their foraging effort at high flow speeds are thus likely dependent on macroalgae ( $P$. laticlavius and $O$. steindachneri) or the small invertebrates that live in macroalgal beds $(M$. dorsalis and T. lucasanum). Macroalgal beds were only found at wave-exposed locations, which likely increased the availability of associated meiofaunal prey. In contrast, parrotfishes (Scarus spp.) feed on a range of benthic prey including sediment and detritus (Choat et al. 2002), and E. galapagensis urchins are likewise generalists (Glynn et al. 1979, Krutwa 2014), both of which focused their feeding at low-flow speeds. Dietary analyses of Galapagos reef fishes could help explain the differences between fish species in the concentration of bites along a flow speed gradient. It is unknown whether urchins and herbivorous fishes compete for benthic algal resources in the Galapagos, but our results suggest that algal resource limitation may occur at wave-sheltered sites. Herbivorous fish biomass was lower in sheltered locations where upright macroalgae were scarce, and both manipulative experiments resulted in greater algal depletion in treatments exposed to both fish and urchins than in partial exclusions. This may indicate competition at low-flow speeds or niche partitioning, whereby urchins utilize low-flow sites and flow-adapted fishes utilize locations with high flow speeds. The increase of fish effects on algal biomass at higher flow speeds where urchins have been excluded is indicative of a greater benefit in terms of available food despite the higher energetic costs implied (Fulton 2007). Future studies should investigate whether more mobile species tend to gain a competitive advantage over slower species as the frequency of environmental stress increases.

Through field observations and manipulative experiments, our study partitioned the effects of increasing wave exposure on subtidal communities into enhanced 
production of macroalgae, species-specific reductions in foraging (Eucidaris, Scarus spp., Stegastes spp.), and enhanced foraging by fast-swimming ( $P$. laticlavius, $M$. dorsalis) and demersal (O. steindachneri) species of herbivorous fishes that require upright macroalgae for food. Although larger stature macroalgae such as kelps can be torn and dislodged by extreme waves (Dayton and Tegner 1984, Hurd 2000), high wave exposure appears to have a net positive effect on the shorter filamentous and foliose algal turfs characteristic of the Galapagos Islands (Thompkins 2017). Ultimately, the restriction of animal foraging by environmental stressors surpassing speciesspecific thresholds is defined by the magnitude, duration, and frequency of stress occurrence (Bijlsma and Loeschcke 2005). The extension of the ESH to incorporate animal mobility can be a useful and general conceptual model for predicting how the limiting frequency of environmental stress is mediated by consumer mobility in both terrestrial and marine ecosystems.

\section{Acknowledgments}

This study was made possible through funding from the National Science Foundation (awards OCE-1061475, OCE1450214, and OCE-1623867) and the Galapagos Conservancy to JDW, and grants from the Rufford Foundation, the American Museum of Natural History, the Institute at Brown for Environment and Society, and the Bushnell Research and Education Fund to RWL. We are deeply grateful to Max Hirschfeld, Paul Tompkins, Etienne Rastoin, Inti Keith, Anaide Aued, Salome Buglass, Blake Hamilton, Fiona Beltram, Camila Lupi, Calvin Munson, and Maya Greenhill for assistance in the lab and in the field. Captain Nelson Ibarra, Captain Wilton Aguirre, and Captain Viko Rosero provided diving logistics aboard their boats. We also thank Arturo Izurieta, Marta Romolereaux, Heinke Jäger, and the Charles Darwin Research Station for field research support, and Danny Rueda, Jorge Carrion, Jenifer Suarez, and the Galapagos National Park for granting us authorization to carry out this investigation (research permit PC-06-16). This publication is contribution number 2285 of the Charles Darwin Foundation for the Galapagos Islands.

\section{Literature Cited}

Abraham, J. O., G. P. Hempson, and A. C. Staver. 2019. Drought-response strategies of savanna herbivores. Ecology and Evolution 9:7047-7056.

Aquilino, K. M., M. E. Bracken, M. N. Faubel, and J. J. Stachowicz. 2009. Local-scale nutrient regulation facilitates seaweed growth on wave-exposed rocky shores in an upwelling system. Limnology and Oceanography 54:309-317.

Baggini, C., Y. Issaris, M. Salomidi, and J. Hall-Spencer. 2015. Herbivore diversity improves benthic community resilience to ocean acidification. Journal of Experimental Marine Biology and Ecology 469:98-104.

Bejarano, S., J. B. Jouffray, I. Chollett, R. Allen, G. Roff, A. Marshell, R. Steneck, S. C. Ferse, and P. J. Mumby. 2017. The shape of success in a turbulent world: wave exposure filtering of coral reef herbivory. Functional Ecology 31:13121324.

Bennett, S., T. Wernberg, T. De Bettignies, G. A. Kendrick, R. J. Anderson, J. J. Bolton, K. L. Rodgers, N. T. Shears, J. C. Leclerc, and L. Lévêque. 2015. Canopy interactions and physical stress gradients in subtidal communities. Ecology Letters 18:677-686.

Bertness, M. D., and R. Callaway. 1994. Positive interactions in communities. Trends in Ecology and Evolution 9:191-193.

Bijlsma, R., and V. Loeschcke. 2005. Environmental stress, adaptation and evolution: an overview. Journal of Evolutionary Biology 18:744-749.

Brandt, M. 2012. Functional roles of biodiversity in the Galapagos Marine Reserve. Dissertation. Brown University, Providence, Rhode Island, USA.

Brandt, M., and P. Guarderas. 2002. Erizos de mar. Pages 396418 in E. Danulat and G. J. Edgar, editors. Reserva Marina de Galápagos. Línea Base de la Biodiversidad. Fundación Charles Darwin/Servicio Parque Nacional Galápagos, Santa Cruz, Galápagos, Ecuador.

Burkepile, D. E., and M. E. Hay. 2006. Herbivore vs. nutrient control of marine primary producers: context-dependent effects. Ecology 87:3128-3139.

Burkepile, D. E., and M. E. Hay. 2008. Herbivore species richness and feeding complementarity affect community structure and function on a coral reef. Proceedings of the National Academy of Sciences 105:16201-16206.

Burrows, M. T. 2012. Influences of wave fetch, tidal flow and ocean colour on subtidal rocky communities. Marine Ecology Progress Series 445:193-207.

Carpenter, R. C. 1986. Partitioning herbivory and its effects on coral reef algal communities. Ecological Monographs 56:345364.

Carr, L., R. Gittman, and J. F. Bruno. 2018. Temperature influences herbivory and algal biomass in the Galápagos Islands. Frontiers in Marine Science 5:279.

Choat, J., K. Clements, and W. Robbins. 2002. The trophic status of herbivorous fishes on coral reefs. Marine Biology 140:613-623.

Connell, J. H. 1961. Effects of competition, predation by Thais lapillus, and other factors on natural populations of the barnacle. Ecological Monographs 31:61-104.

Connell, J. H. 1975. Some mechanisms producing structure in natural communities: a model and evidence from field experiments. Pages 460-490 in M. Cody and J. Diamond, editors. Ecology and evolution of communities. Harvard University Press, Boston, Massachusetts, USA.

Dahlhoff, E. P., B. A. Buckley, and B. A. Menge. 2001. Physiology of the rocky intertidal predator Nucella ostrina along an environmental stress gradient. Ecology 82:2816-2829.

Dayton, P. K., and M. J. Tegner. 1984. Catastrophic storms, El Niño, and patch stability in a southern California kelp community. Science 224:283-285.

Dee, L. E., J. D. Witman, and M. Brandt. 2012. Refugia and top-down control of the pencil urchin Eucidaris galapagensis in the Galápagos Marine Reserve. Journal of Experimental Marine Biology and Ecology 416:135-143.

Denny, M. 2014. Biology and the mechanics of the wave-swept environment. Princeton University Press, Princeton, New Jersey, USA.

Denny, M., and S. D. Gaines. 1990. On the prediction of maximal intertidal wave forces. Limnology and Oceanography 35:1-15.

Denny, M. W., T. L. Daniel, and M. Koehl. 1985. Mechanical limits to size in wave-swept organisms. Ecological Monographs 55:69-102.

Edgar, G. J., S. Banks, J. M. Farina, M. Calvopina, and C. Martinez. 2004. Regional biogeography of shallow reef fish and macro-invertebrate communities in the Galapagos archipelago. Journal of Biogeography 31:1107-1124.

Edgar, G. J., S. A. Banks, M. Brandt, R. H. Bustamante, A. Chiriboga, S. A. Earle, L. E. Garske, P. W. Glynn, J. 
S. Grove, and S. Henderson. 2010. El Niño, grazers and fisheries interact to greatly elevate extinction risk for Galapagos marine species. Global Change Biology 16:2876-2890.

Edwards, D. C., D. O. Conover, and F. Sutter. 1982. Mobile predators and the structure of marine intertidal communities. Ecology 63:1175-1180.

Ellis, J. C., M. J. Shulman, M. Wood, J. D. Witman, and S Lozyniak. 2007. Regulation of intertidal food webs by avian predators on New England rocky shores. Ecology 88:853863.

Floeter, S. R., W. Krohling, J. L. Gasparini, C. E. Ferreira, and I. R. Zalmon. 2007. Reef fish community structure on coastal islands of the southeastern Brazil: the influence of exposure and benthic cover. Environmental Biology of Fishes 78:147160.

Froese, R., and D. Pauly. 2019. FishBase. www.fishbase.org

Fulton, C. 2007. Swimming speed performance in coral reef fishes: field validations reveal distinct functional groups. Coral Reefs 26:217-228.

Fulton, C. J., and D. R. Bellwood. 2005. Wave-induced water motion and the functional implications for coral reef fish assemblages. Limnology and Oceanography 50:255-264.

Glynn, P. W., G. M. Wellington, and C. Birkeland. 1979. Coral reef growth in the Galapagos: limitation by sea urchins. Science 203:47-49.

Grove, J. S., and R. J. Lavenberg. 1997. The fishes of the Galápagos islands. Stanford University Press, Palo Alto, California, USA.

Hatcher, B. 1981. The interaction between grazing organisms and the epilithic algal community of a coral reef: a quantitative assessment, vol. 2, Pages 515-524 in Proceedings of the 4 th international coral reef symposium.

Hay, M. E. 1981. Herbivory, algal distribution, and the maintenance of between-habitat diversity on a tropical fringing reef. American Naturalist 118:520-540.

He, Q., and M. D. Bertness. 2014. Extreme stresses, niches, and positive species interactions along stress gradients. Ecology 95:1437-1443

Horn, M. H., K. L. Martin, and M. A. Chotkowski. 1999. Intertidal fishes: life in two worlds. Academic Press, San Diego, California, USA.

Houvenaghel, G. 1978. Oceanographic conditions in the Galapagos Archipelago and their relationships with life on the islands. Pages 181-200 in R. Boje and M. Tomczak, editors. Upwelling ecosystems. Springer, Berlin, Germany.

Humboldt, A. V., and A. Bonpland. 1805. Essai sur la géographie des plantes, Chez Levrault, Schoell, Paris, France.

Hurd, C. L. 2000. Water motion, marine macroalgal physiology, and production. Journal of Phycology 36:453-472.

Hurlbert, S. H. 1984. Pseudoreplication and the design of ecological field experiments. Ecological Monographs 54:187-211.

Irons, D. B., R. G. Anthony, and J. A. Estes. 1986. Foraging strategies of glaucous-winged gulls in a rocky intertidal community. Ecology 67:1460-1474.

Irving, A. D., and J. D. Witman. 2009. Positive effects of damselfish override negative effects of urchins to prevent an algal habitat switch. Journal of Ecology 97:337-347.

Kawamata, S. 1998. Effect of wave-induced oscillatory flow on grazing by a subtidal sea urchin Strongylocentrotus nudus (A. Agassiz). Journal of Experimental Marine Biology and Ecology 224:31-48.

Kraft, N. J., P. B. Adler, O. Godoy, E. C. James, S. Fuller, and J. M. Levine. 2015. Community assembly, coexistence and the environmental filtering metaphor. Functional Ecology 29:592-599.
Krutwa, A. 2014. Small-scale differences in tropical subtidal rocky reef communities of Floreana Island. Dissertation. Universität Bremen, Bremen, Germany.

Leigh, E. G., R. T. Paine, J. F. Quinn, and T. H. Suchanek. 1987. Wave energy and intertidal productivity. Proceedings of the National Academy of Sciences of the United States of America 84:1314-1318.

Leisler, B. 1992. Habitat selection and coexistence of migrants and Afrotropical residents. Ibis 134:77-82.

Leonard, G. H., J. M. Levine, P. R. Schmidt, and M. D. Bertness. 1998. Flow-driven variation in intertidal community structure in a Maine estuary. Ecology 79:1395-1411.

Lewis, S. M. 1986. The role of herbivorous fishes in the organization of a Caribbean reef community. Ecological Monographs 56:183-200.

Liao, J. C. 2007. A review of fish swimming mechanics and behaviour in altered flows. Philosophical Transactions of the Royal Society B 362:1973-1993.

Menge, B. A. 1978. Predation intensity in a rocky intertidal community. Effect of an algal canopy, wave action and desiccation on predator feeding rates. Oecologia 34:17-35.

Menge, B. A., A. M. Olson, and E. P. Dahlhoff. 2002. Environmental stress, bottom-up effects, and community dynamics: integrating molecular-physiological and ecological approaches. Integrative and Comparative Biology 42:892-908.

Menge, B. A., and J. P. Sutherland. 1976. Species diversity gradients: synthesis of the roles of predation, competition, and temporal heterogeneity. American Naturalist 110:351-369.

Menge, B. A., and J. P. Sutherland. 1987. Community regulation-variation in disturbance, competition, and predation in relation to environmental-stress and recruitment. American Naturalist 130:730-757.

Morrison, D. 1988. Comparing fish and urchin grazing in shallow and deeper coral reef algal communities. Ecology 69:1367-1382.

Nathan, R., W. M. Getz, E. Revilla, M. Holyoak, R. Kadmon, D. Saltz, and P. E. Smouse. 2008. A movement ecology paradigm for unifying organismal movement research. Proceedings of the National Academy of Sciences of the United States of America 105:19052-19059.

Ojeda, F. P., and A. A. Munoz. 1999. Feeding selectivity of the herbivorous fish Scartichthys viridis: effects on macroalgal community structure in a temperate rocky intertidal coastal zone. Marine Ecology Progress Series 184:219-229.

Oliver, T. H., et al. 2015. Biodiversity and resilience of ecosystem functions. Trends in Ecology and Evolution 30:673-684.

Paine, R. T., and S. A. Levin. 1981. Intertidal landscapes: disturbance and the dynamics of pattern. Ecological Monographs 51:145-178.

Pimm, S. L. 1982. Food webs. University of Chicago Press, Chicago, Illinois, USA.

Quimbayo, J. P., M. S. Dias, M. Kulbicki, T. C. Mendes, R. W. Lamb, A. F. Johnson, O. Aburto-Oropeza, J. J. Alvarado, A. A. Bocos, and C. E. Ferreira. 2018. Determinants of reef fish assemblages in tropical oceanic islands. Ecography 42:77-87.

Sanders, H. 1969. Benthic marine diversity and the stabilitytime hypothesis. Page 71 in Brookhaven Symposia in Biology.

Siddon, C. E., and J. D. Witman. 2003. Influence of chronic, low-level hydrodynamic forces on subtidal community structure. Marine Ecology Progress Series 261:99-110.

Steneck, R. S., D. R. Bellwood, and M. E. Hay. 2017. Herbivory in the marine realm. Current Biology 27:R484-R489.

Steneck, R. S., and M. N. Dethier. 1994. A functional group approach to the structure of algal-dominated communities. Oikos 69:476-498. 
Stephens, M. A. 1974. EDF statistics for goodness of fit and some comparisons. Journal of the American Statistical Association 69:730-737.

Steudel, B., A. Hector, T. Friedl, C. Lofke, M. Lorenz, M. Wesche, and M. Kessler. 2012. Biodiversity effects on ecosystem functioning change along environmental stress gradients. Ecology Letters 15:1397-1405.

Stuart-Smith, R. D., et al. 2013. Integrating abundance and functional traits reveals new global hotspots of fish diversity. Nature 501:539-542.

Taylor, D. I., and D. R. Schiel. 2010. Algal populations controlled by fish herbivory across a wave exposure gradient on southern temperate shores. Ecology 91:201-211.

Thompkins, P. 2017. Historical knowledge, variation in community composition, ecotrophic parameterization, and invasive species of macroalgae in the Galapagos archipelago. Dissertation. Universität Bremen, Bremen, Germany.

Tuya, F., J. Cisneros-Aguirre, L. Ortega-Borges, and R. Haroun. 2007. Bathymetric segregation of sea urchins on reefs of the Canarian Archipelago: role of flow-induced forces. Estuarine, Coastal and Shelf Science 73:481-488.

Tuya, F., and R. J. Haroun. 2006. Spatial patterns and response to wave exposure of shallow water algal assemblages across the Canarian Archipelago: a multi-scaled approach. Marine Ecology Progress Series 311:15-28.

Walters, V. 1962. Body form and swimming performance in the scombroid fishes. American Zoologist 2:143-149.

Weiher, E., and P. Keddy. 2001. Ecological assembly rules: perspectives, advances, retreats. Cambridge University Press, Cambridge, UK.
Witman, J. D. 1987. Subtidal coexistence: storms, grazing, mutualism, and the zonation of kelps and mussels. Ecological Monographs 57:167-187.

Witman, J. D., M. Brandt, and F. Smith. 2010. Coupling between subtidal prey and consumers along a mesoscale upwelling gradient in the Galapagos Islands. Ecological Monographs 80:153-177.

Witman, J. D., and P. K. Dayton. 2001. Rocky subtidal communities. Pages 339-366 in M. D. Bertness, S. D. Gaines, and M. E. Hay, editors. Marine community ecology. Sinauer, Sunderland, Massachusetts, USA.

Witman, J. D., R. J. Etter, and F. Smith. 2004. The relationship between regional and local species diversity in marine benthic communities: a global perspective. Proceedings of the National Academy of Sciences of the United States of America 101:15664-15669.

Witman, J. D., and K. R. Grange. 1998. Links between rain, salinity, and predation in a rocky subtidal community. Ecology 79:2429-2447.

Witman, J. D., F. Smith, and M. Novak. 2017. Experimental demonstration of a trophic cascade in the Galápagos rocky subtidal: effects of consumer identity and behavior. PLoS One 12:e0175705.

Witman, J. D., and T. H. Suchanek. 1984. Mussels in flow: drag and dislodgement by epizoans. Marine Ecology Progress Series 16:259-268.

Zimmerhackel, J. S., A. C. Schuhbauer, P. Usseglio, L. C. Heel, and P. Salinas-de-León. 2015. Catch, bycatch and discards of the Galapagos Marine Reserve small-scale handline fishery. PeerJ 3:e995.

SUPPORTING INFORMATION

Additional supporting information may be found in the online version of this article at http://onlinelibrary.wiley.com/doi/ 10.1002/ecy.2910/suppinfo

\section{Data Availability}

Data are available from the Dryad Digital Repository: https://doi.org/10.5061/dryad.v6wwpzgqx 